\title{
MOVIMENTOS DE MASSA E VULNERABILIDADE AMBIENTAL NA ESTRADA ABRAÃO - DOIS RIOS, ILHA GRANDE (R J)
}

\author{
Jonathan Araujo Barreto de Souza ${ }^{(\mathrm{a})}$, Tadeu Tostes de Souza ${ }^{(\mathrm{b})}$, Ana Beatris Costa Farias ${ }^{(\mathrm{c})}$ \\ (a) Núcleo de Ensino e Pesquisa em Planejamento Territorial, Instituto de Geografia, Universidade do Estado do \\ Rio de Janeiro, <jonathan93.uerj@gmail.com> \\ (b) Núcleo de Ensino e Pesquisa em Planejamento Territorial, Instituto de Geografia, Universidade do Estado do \\ Rio de Janeiro, <tadeu.tostes@hotmail.com> \\ (b) Núcleo de Ensino e Pesquisa em Planejamento Territorial, Instituto de Geografia, Universidade do Estado do \\ Rio de Janeiro, <anabeatrizcfarias@gmail.com>
}

\section{Eixo: GEOGRAFIA FISICA E DESASTRES NATURAIS}

\begin{abstract}
RESUMO
A Ilha Grande é distrito de Angra dos Reis e localiza-se no litoral sul do estado do Rio de Janeiro. Diferentes Unidades de Conservação inserem-se nesse território insular que, nas últimas décadas, tem sido visitado por turistas. O recorte espacial abrange o percurso entre as enseadas de Abraão e Dois Rios, estrada com cerca de $12 \mathrm{~km}$ de extensão. De Estrada da Colônia, à época do Presídio, passou a ser chamada de Trilha T14, à época da criação de áreas protegidas, e poderá ser considerada como Estrada-Parque, de acordo com recente proposta do governo do Estado do Rio de Janeiro no momento atual em que o turismo é a atividade econômica que predomina em quase toda a ilha. O objetivo principal é o de realizar levantamento dos escorregamentos ao longo da estrada bem como o de cicatrizes para subsidiar o manejo e manter a paisagem em estado natural ou seminatural, dentro dos propósitos do Parque.
\end{abstract}

Palavras-chave: unidades de conservação, impactos ambientais, Ilha Grande.

\section{Introdução}

O território da Ilha Grande está localizado no litoral sul do estado do Rio de Janeiro (Figura 1). Distrito do município de Angra dos Reis, não se encontra totalmente adensado, mas guarda características ambientais que são atrativos para os visitantes e turistas. O presente trabalho identifica os fatores causadores e/ou potencializadores da vulnerabilidade ambiental no recorte espacial em questão, a Estrada Abraão - Dois Rios ou Trilha T-14 que conecta as respectivas enseadas.

O objetivo principal é identificar as modificações de uso e ocupação do solo na estrada para fins de planejamento territorial, pois, as enseadas que essa estrada conecta apresentam aspectos físicos semelhantes (enseadas para onde convergem as bacias hidrográficas de diferentes portes), mas diferentes restrições de uso do solo de acordo com as unidades de conservação APA e PARQUE. A Vila de Abraão está inserida na APA (Área de Proteção Ambiental Tamoios), tem elevada taxa de ocupação e predominam usos residencial e turístico. O Lugarejo (segundo o IBGE) de Dois Rios situase dentro da área do PARQUE (Parque Estadual da Ilha Grande), tem ocupação restrita ainda dos tempos do presídio em funcionamento e predominam os usos acadêmico científico (CEADS - Centro 


\section{OS DESAFIOS DA GEOGRAFIA FÍSICA NA FRONTEIRA DO CONHECIMENTO \\ Instituto de Geociências - Unicamp \\ Campinas - SP \\ 28 de Junho à 02 de Julho de 2017}

de Estudos Ambientais e Desenvolvimento Sustentável) e de proteção ambiental com restrições para permanência humana.

A metodologia baseia-se na 'bacia hidrográfica' como referência espacial do território protegido e, possibilita realizar análise integrada que relacione os processos morfogenéticos e os pedogenéticos com foco no entendimento da vulnerabilidade ambiental dessa área. A bacia hidrográfica como unidade de planejamento é comumente usada por constituir os três níveis de abordagem sistemática (compartimentação morfológica, estrutura superficial e fisiologia da paisagem) apresentados por Ab'Saber (1969) e, aliados a essa abordagem, destaca-se a análise ambiental proposta por Santos (2004) que considera as inter-relações nos seus diversos níveis e propõe a divisão de 'Bacia Ambiental' (Rosa, 2010). Com base nas limitações, qualquer intervenção oriunda das atividades socioeconômicas deve ser analisada para verificar sua compatibilidade com a capacidade de suporte do ambiente e comunidades vinculadas.

$\mathrm{Na}$ ilha, as diferentes territorialidades deixam prevalecer na atualidade dois territórios, o da proteção da natureza e do turismo. Ambos são regidos por planejamento municipal e estadual que apontam diretrizes de uso e ocupação do solo e restrições a partir da delimitação de zonas específicas concordantes com a legislação ambiental. Esses planos apresentam falhas ou lacunas na esfera da gestão pública que possibilitam a intensificação de impactos ambientais identificados nas enseadas (núcleos populacionais), nas trilhas (eixos de circulação) ou no interior da floresta tropical (visitação e pesquisa).

Figura 1: Localização da Ilha Grande

\section{Unidade de análise}

A unidade espacial de análise deste estudo baseia-se na bacia hidrográfica por ser uma unidade integradora entre os impactos causados ao meio físico e à apropriação social do espaço. Lima (2005:9) apresenta a caracterização da bacia hidrográfica como um meio para determinação de controle e estabelecimento do território e, no caso da Ilha Grande, poderá contribuir no ordenamento do uso do solo e na proteção ambiental visto que a atividade turística vem se intensificando e potencializando a ocorrência de impactos ambientais. A partir dessa base espacial - bacia hidrográfica - os acessos são identificados e também utilizados como unidade espacial de análise.

$\mathrm{Na}$ área de estudo, esses acessos são principalmente as vias nos espaços "urbanizados", as trilhas que promovem a mobilidade entre esses espaços (enseadas) cortando o relevo e passando por ambientes de floresta e a estrada Abraão - Dois Rios. Através dos acessos os aspectos ambientais e problemas 


\section{OS DESAFIOS DA GEOGRAFIA FÍSICA NA FRONTEIRA DO CONHECIMENTO \\ Instituto de Geociências - Unicamp \\ Campinas - SP \\ 28 de Junho à 02 de Julho de 2017}

físicos ou biológicos (compactação do solo, aumento da largura das trilhas, alterações na cobertura vegetal, dentre outros) são observados, podendo-se prever uma melhor distribuição geográfica e limitações da ocupação humana.

Para complementar a análise integrada, foram identificados os limites e as restrições legais de cada unidade de conservação ambiental neste recorte espacial. Desse modo, teremos um mapa da ilha (e do recorte espacial do estudo) identificando as bacias e suas fragilidades ambientais (de acordo com Rosa, 2010), além da identificação dos traçados das vias que podem potencializar essas fragilidades associadas às diretrizes legais das unidades de conservação. A espacialização e a integração desses dados poderão indicar ações mais específicas de planejamento para a Estrada e as Enseadas em questão.

\section{Trabalho de Gabinete e Campo}

A primeira etapa do trabalho foi dividida em duas partes. Na primeira, foram realizadas pesquisas de gabinete, com auxílio de artigos, monografias e teses do acervo do Núcleo de Estudo e Pesquisa em Planejamento Territorial (NEPPT). Tais pesquisas foram utilizadas para o reconhecimento das características físicas (solos, geomorfologia, hidrologia e geologia) e Antrópicas (ocupações, enseadas, trilhas). Na segunda, foi realizada uma campanha de campo, onde pudemos identificar os processos nas encostas, descrevê-los e espacializá-los.

Por se tratar de um relevo acidentado, associado a um clima úmido e uma alta pluviosidade, o Litoral sul do Rio de Janeiro possui uma grande incidência de deslizamentos. Ao percorrer a trilha T-14 foram mapeados um total de 60 pontos de interesse com o auxílio de um GPS, que estão divididos em pontos de escorregamento antigos (com cobertura vegetal primária), escorregamentos recentes (cicatrizes abertas), pontos de erosão, pontos de retirada de solo para a manutenção da estrada (degradação antrópica).

Também foram observados pontos de ocupação de samambaias (Gleichenia sp.), tais samambaias podem ser vistas como uma praga em alguns pontos, uma vez que impedem o crescimento de outras plantas, devido a sua extensão e densidade que impede a passagem do Sol. As Gleichenia sp., também são indicadores de deslizamentos anteriores, pois fazem parte da sucessão ecológica, sendo plantas do primeiro estágio de ocupação.

A trilha em si, apresenta sulcos causados pelo escoamento superficial, e um conjunto de artefatos como paralelepípedos, entulho de restos de material de construção, tais artefatos eram utilizados para a manutenção da estrada na época do presídio. 


\section{OS DESAFIOS DA GEOGRAFIA FÍSICA NA FRONTEIRA DO CONHECIMENTO \\ Instituto de Geociências - Unicamp \\ Campinas - SP \\ 28 de Junho à 02 de Julho de 2017}

As marcações foram feitas em dois dias, partindo do divisor de águas (Britador) como chamam os moradores para Abraão e para Dois Rios. No primeiro dia, as medições foram feitas no sentido Britador-Dois Rios, parte aparentemente menos íngreme da trilha, porém foi a parte que apresentou o maior número de pontos de interesse, um total de 39 pontos, onde também foi possível observar que é a parte da trilha com menor proteção, apresentando uma insolação alta no meio da trilha, a falta de cobertura vegetal, pode influenciar muito no efeito splash, tal etapa de medição de sulcos será feita em uma próxima visita a ilha. No segundo dia o percurso foi feito no sentido Britador-Abraão, ponto aparentemente mais íngreme, porém com o menor número de escorregamentos, tal parte do percurso possui uma maior cobertura vegetal ao longo da trilha, com as copas das árvores auxiliando na proteção contra o efeito splash e com uma mata mais fechada nas laterais evitando assim os deslizamentos de terra.

\section{Resultados Preliminares}

Os mapas gerados por Rosa (2010), em especial o de Bacias Ambientais e o de Fragilidade Ambiental foram sobrepostos para individualizar este setor do território da Ilha Grande que foi cortado por estrada ao longo de $12 \mathrm{~km}$ no interior do Parque Estadual da Ilha Grande. As Bacias Ambientais em destaque são aquelas que possuem relevos com declividade inferior a $20 \%$, com amplitudes altimétricas superiores a 400 metros, constituídas por encostas íngremes associados a colinas, com vegetação de alto porte, com predomínio de solos jovens pouco profundos, cascalhentos e com permeabilidade muito baixa sendo propícios ao risco de processos erosivos e; aquelas que possuem relevos com declividade inferior a $20 \%$, com amplitudes altimétricas superiores a 400 metros, constituídas por encostas íngremes associados a colinas, com vegetação de alto porte, com predomínio de solos jovens pouco profundos, cascalhentos e com permeabilidade muito baixa sendo propícios ao risco de processos erosivos. Estas bacias estão associadas às enseadas das quais os núcleos populacionais contam com a atuação do estado, do município e de ONGs e Associações, e apresentam conflitos de interesse entre eles.

Quanto a fragilidade ambiental, as enseadas e a estrada vão apresentar fragilidade muito baixa a baixa, média e alta, variando entre as unidades de relevo mais plano a abrupto, solos jovens, com ou sem a presença de vegetação.

O trabalho final será representado por mapa síntese contendo os pontos de interesse (movimentos de massa e cicatrizes) para fins de planejamento ambiental e territorial.

\section{Bibliografia}


Bigarella, J. J. e SANTOS, G. F. dos. Estrutura e Origem das Paisagens Tropicais e Subtropicais. Florianópolis. Ed UFSC, 2003 v.3 p. $884-889$.

FERNANDES et all, 2001 .as Encostas: Avaliação de Metodologias e Aplicação de Modelo de Previsão de Áreas Susceptíveis.

KALIKI, M. A. G. DA SILVA. Diagnostico da Estrada Abraão-Dois Rios na ilha grande (RJ) e a proposta de Estrada-Parque no âmbito do planejamento ambiental. Monografia, Instituto de Geografia, UERJ. 2014.

ROSA, MATEUS DA SILVA. Bacias Ambientais da Ilha Grande: adequação da escala de análise para o planejamento ambiental. Monografia, Instituto de Geografia, UERJ. 2010.

SANTOS, R.F. Planejamento ambiental: teoria e prática. Oficina de textos, 2004. 